\title{
Review
}

Mojtaba Tadayonifar*, Mahnaz Entezari and

Mostafa Bahraman

\section{Investigating the relationship between linguistic focus of recasts, learning styles and noticing}

https://doi.org/10.1515/cercles-2020-2008

\begin{abstract}
The efficacy of Corrective Feedback (CF) is contingent on various factors; conflicting results have been obtained regarding the roles of individual differences and the linguistic focus of CF. The current study investigated the relationship between the linguistic focus of recasts (the most common CF type) and noticing. It further explored the possible relationship between learning styles and recast noticing. The learning styles of 25 intermediate Iranian EFL learners were determined through the VARK questionnaire. During the participants' story retelling tasks, the researchers provided recasts in response to their grammatical, lexical, and phonological errors. The class presentations were audiotaped, and recasts were highlighted. Online and retrospective methods of measuring noticing were used. Chi-Square tests indicated that there were significant differences among the participants' noticing in general and in noticing of grammatical, lexical, and phonological recasts in particular. The results of post hoc analysis revealed that the auditory-style participants received the highest noticing rate and the kinesthetic style the least. The study further indicated that learners whose learning style was auditory better noticed grammatical recasts, learners whose learning style was mixed better noticed lexical recasts, and visual learners better noticed phonological recasts.
\end{abstract}

Keywords: learning styles, recasts, noticing, stimulated recall

\footnotetext{
*Corresponding author: Mojtaba Tadayonifar, English Translation Department, Kashmar Higher Education Institute, Kashmar, Iran, E-mail: mtadayon.253@gmail.com. https://orcid.org/00000002-1448-4216

Mahnaz Entezari and Mostafa Bahraman: English Translation Department, Kashmar Higher Education Institute, Kashmar, Iran, E-mail: mahnaz.entezari23@gmail.com (M. Entezari), msph_bahraman@yahoo.com (M. Bahraman)
} 


\section{Introduction}

One of the key questions facing theorists, researchers, and teachers is whether feedback should be provided in response to learners' linguistic errors and if so, how it should be provided to enhance L2 learning (Choi and Li 2012; Suzuki et al. 2019). This question has been investigated from both theoretical and empirical perspectives. Theoretically, the focus on form approach suggests that drawing learners' attention to their erroneous utterances while engaging in meaningful interaction facilitates L2 development (Long 2015). Empirically, a number of metaanalyses have provided evidence that Corrective Feedback (CF) can be effective for interlanguage development (e.g., Li 2010; Lyster and Saito 2010). Corrective feedback (CF), which is a reaction to the learner's erroneous utterances to promote L2 development (Ellis 2006), comes in a variety of forms. Lyster and Ranta (1997) categorized them into six groups including explicit correction, elicitation, clarification request, metalinguistic cue, repetition, and recasts.

\subsection{Recasts}

Nicholas, Lightbown, and Spada (2001: 720) defined recasts as "the teachers' correct restatement of learners' incorrectly formed utterance”. Recasts as the most commonly used CF technique in the language classrooms across contexts and languages (Sheen 2004, 2006) have been the subject of a plethora of research with contrasting views. While some researchers advocated recasts as an effective $\mathrm{CF}$ technique (Erlam and Loewen 2010), some studies showed no L2 development as a result of providing recasts (Lyster and Saito 2010; Sheen 2007). However, various factors might have an impact on the effectiveness of CF in general and recasts in particular. Previous research has considered some of these influential factors including timing (Li et al. 2016), linguistic targets and their salience (Li 2013; Sheen 2004; Suzuki et al. 2019), mode of communication (Parlak and Ziegler 2017), learner age and proficiency (Kaivanpanah et al. 2012; Li 2013), instructor characteristics (Gurzynski-Weiss 2016), CF characteristics and types (Al-Surmi 2012; Li 2013; Loewen and Sato 2018; Sheen 2006; Suzuki et al. 2019; Zhao and Ellis 2020), and individual differences (Goo 2012; Granena and Y1lmaz (2018)).

Individual differences, the characteristics that differentiate individuals from each other; have been found to be the most consistent predictors of L2 learning success (Dörnyei 2005). Some meta-analyses have also indicated that the effectiveness of CF varies depending on internal and external learner variables (Li 2010). For example, Sheen (2007) investigated the moderating effects of 
language aptitude and the learners' attitudes towards error correction. Goo (2012) and Kim et al. (2015) probed the impacts of metalinguistic feedback and recasts across learners with different working memory capacity. Sheen (2008) took into account the learners' level of language anxiety and the efficacy of recasts. By considering CF as "information" given to the learners in response to their erroneous utterances, the way the learners perceive the "information" (students' learning styles) would have an impact on the efficacy of feedback given (Wahyuni 2017).

\subsection{Learning styles}

Oxford (2011) defined learning styles as general approaches that learners use in the learning of a subject, acquiring a language, or dealing with a difficult problem. The importance of learning styles in teaching has long been investigated but conflicting results have been obtained. Some researchers believe that acting based on students' learning styles can positively affect the teaching process (Bhat 2014). Other researchers believe that there is quite a bit of disconfirming evidence that learning styles provide a foundation for teaching (Cuevas 2015; Hussman and O'Loughlin 2018; Willingham et al. 2015). Willingham et al. (2015) argued that more studies are required to determine whether teaching to learning styles helps students because it is difficult to prove that something does not exist. Feedback provision occurs during the teaching process; therefore, more research is also needed to address the issue of whether matching CF to the students' learning styles enhances the efficacy of correction which, in turn, affects the noticeability of the correction (Ferris 2010).

\subsection{Measures of noticing}

Noticing is regarded as an important part of the process of learning a new language. Schmidt (1990) claimed that what is noticed becomes intake which is necessary for L2 learning. To be effective, recasts must be noticed by the learners. Uptake, learners' immediate response following feedback, has been closely related to noticing (Mackey 1999, cited in Sheen 2006), although this claim is contentious. Uptake is an optional discourse move (Ellis et al. 2001). Thus, while successful uptake can be considered to provide evidence of noticing, the reverse does not necessarily hold true - learners may notice the corrected form even if they do not uptake it. However, Mackey et al. (2000) found that where uptake occurred, learners generally showed accurate perceptions about recasts. Taken together, 
these findings suggest that uptake can serve as one measure of learners' noticing. Therefore, uptake is considered the first sign of noticing in the current study, but as mentioned earlier, learners may notice the corrected form even if they do not uptake it. Therefore, there is a need for another tool to examine learners' perception of recasts. Stimulated recall is the tool that some researchers including Mackey et al. (2000), Sheen (2004) and many others have used to examine learners' perception of recasts.

\subsection{The linguistic focus of corrective feedback and noticing}

Previous research has posited that feedback on certain aspects can be noticed more readily than others. For example, Mackey et al. (2000) provided evidence that learners' perceptions about lexical, semantic, and phonological recasts were relatively more accurate than morpho-syntactic recasts. Kim and Han (2007) also indicated that phonological recasts received the most amount of noticing which was followed by morphological and lexical recasts, and the syntactic recasts led to the least amount of uptake. Sheen (2006) indicated that phonological recasts yielded a higher rate of uptake than syntactic recasts. In contrast with these findings, Mackey et al. (2007) also found that students identified the corrective intent of morphological, lexical, and syntactic feedback more than phonological feedback. Similarly, conflicting results have been obtained regarding the role of individual differences and noticing. While Trofimovich et al. (2007) did not find any relationship between individual differences and the level of noticing, Bigelow et al. 2012 found positive correlation between individual characteristics and noticing. Thus, the current study aims to shed more light on the issue of whether the recast noticing rate is different when certain aspects (phonology, lexis, syntax) of language are targeted. It further aims to report the possible relationship between learning styles and recast noticing.

\section{Literature review}

Recasts as the most common CF type have been investigated from various angles. Some studies compared the effectiveness of recasts to other CF types. Some researches explored the characteristics of recasts in order to find the most effective forms of recasts. Teachers' and learners perceptions towards recasts have also been the focus of some studies. Finally, some studies explored the relationship between individual differences and recast noticing. Some of these studies are reviewed below. 


\subsection{Recasts versus other corrective feedback}

Some studies in this area indicated that there was no difference among CF types regarding their efficacy. For example, Zhao and Ellis (2020) compared the effects of implicit recasts and prompts on the acquisition of third person $-s$ while the participants were completing communicative tasks. Findings showed no significant difference in the accuracy gains of the groups. Similarly, Granena and Yllmaz (2018) explored the efficacy of recasts and explicit corrections on learners' grammatical sensitivity. They found that neither recasts nor explicit corrections were effective in changing L2 learning outcomes.

Some studies indicated the preference of one type of CF to the others. For example, Sato and Loewen (2018) investigated the effects of four types of CF, namely metacognitive instruction plus clarification requests, metacognitive instruction plus recasts, recasts only, and clarification requests only on learning the third-person singular $-s$ and possessive determiners. The results showed that recasts had minimal impact on the target structures, but clarification requests could support language development. Other studies investigated the factors influencing the efficacy of CF. For instance, Choi and Li (2012) investigated the occurrence of CF and uptake in child ESOL classes showed that children preferred recasts and explicit correction as they yielded higher uptake rates than prompts.

\subsection{Recast features and their effectiveness}

Sato (2016) investigated the effects of recasts in terms of the error types, length, and degree of change in the recasts. The results indicated that phonological recasts yielded the most noticing, followed by lexical recasts, and grammatical recasts showed the lowest noticing rate. No difference was found regarding the recast length or number of changes. $\mathrm{Li}$ (2013) explored the interactions between proficiency, feedback type, and the nature of linguistic target. The study underscored the importance of taking an interactional approach to the investigation of $\mathrm{CF}$ as both the proficiency levels and the linguistic targets affected efficacy and sustainability of CF. Al-Surmi (2012) investigated the effects of utilizing different types of recasts (i.e., declarative or interrogative) on students' noticing of morphosyntactic errors. The study revealed that there was no significant difference between recast types in terms of noticing. Sheen (2006) also found that explicit recasts led to more instances of uptake than implicit recasts as they are focused on a single linguistic feature which makes the reformulated item salient to learners. 


\subsection{Perceptions of recasts}

In order to find factors affecting choices of a particular type of $\mathrm{CF}$, the perceptions and preferences of teachers and learners have been the focus of some studies. Kaivanpanah et al. 2012, for example, compared learners' views on recasts and elicitations across language proficiencies. They found that learners with higher proficiency levels tended to favor elicitations more than recasts. Yoshida (2008) provided more evidence of a learner preference for elicitation. While the findings of the previous studies yielded conflicting results, Mackey et al. (2007) indicated that learners' perceptions and teachers' intentions about the linguistic target of CF overlapped the most when CF targeted lexical errors.

\subsection{Learning styles and corrective feedback}

Previous research has tried to understand the contribution of learning styles, as one important aspect of individual differences, to the efficacy of corrective feedback. These studies can be divided into two categories: (a) studies that found positive moderating effects of learning styles on the effectiveness of CF, and (b) studies in which no correlation was found between learning styles and the efficacy of $\mathrm{CF}$.

Hashemian and Farhangju (2018) explored the moderating effects of learning styles on the efficacy of metalinguistic written corrective feedback. The results showed that learning style can moderate the effectiveness of CF. Rassaei (2015) examined the hypothesis that learners with different learning styles might benefit in different ways from recasts. His study provided more evidence that learning styles can influence the efficacy of recasts. Rahimi (2015) also found a strong relationship between learners' learning styles and their successful short-term and long-term retention of CF. Evans and Waring (2011) explored the relationship between student teachers' gender, cognitive styles, and their feedback preferences. The study revealed that a significant difference existed between students with different gender and cognitive styles and their perceptions of feedback. Yoshida (2008) investigated teachers' choice and learners' preferences for corrective feedback types. The findings indicated that teachers' choice of CF type was influenced by their learning styles and language abilities.

In contrast, Wahyuni (2017) probed the impacts of providing different feedback on the writing quality of students with different cognitive styles. The results showed that learning style does not moderate the influence of different feedback on writing quality of the students. Tasdemir and Arslan (2018), who investigated the relationship between students' learning styles and their preferences for oral 
corrective feedback, provide evidence that the concept of learning styles is irrelevant for understanding learner feedback preference. The conflicting results in this area motivated the present study to provide the literature with more evidence for the moderating effects of learning styles and the linguistic focus of CF in the form of recasts on the noticing rate of the learners.

\section{The present study}

The relationship between the variables of the study is investigated through the following research questions.

\subsection{Research questions}

1. Are there any significant differences among Iranian EFL students' noticing of grammatical, lexical, and phonological recasts?

2. What is the relationship between Iranian EFL students' learning styles and recasts noticing?

3. What is the relationship between Iranian EFL students' learning styles and the linguistic focus of recast?

\subsection{Participants}

Twenty-five university students took part in this study. They consisted of five male and 20 female students aged between 20 and 22. They were English translation students taking a course involving the oral re-telling of short stories in a college in Iran. ${ }^{1}$ All of the participants were characterized as intermediate proficiency according to the college criteria for passing the previous courses to reach the current course. Their classes were held once a week, and each session lasted for $90 \mathrm{~min}$. They were verbally announced in class, then information about the aims of the study, time commitment, and the use of their data for research purposes was presented through written materials.

1 Oral Reproduction of Stories is a two-credit course for English students (translation, literature, and teaching). The course is intended to stretch students' ideas of what a story is and how it can be retold. The students are encouraged to go beyond plain summaries and paraphrases, and to appreciate narratological coherence and chronological accuracy. 


\subsection{Instruments}

\subsubsection{Story retelling tasks}

The participants were required to choose five stories out of 20 that the instructor had provided. They were asked to prepare themselves for retelling the story in their own words in a time limit of 5-10 min based on the length and difficulty of the story.

\subsubsection{Fleming's VARK learning style questionnaire}

The most common method of identifying learning styles in practice is based on the type of sensory modality which one prefers when using and evaluating new information (Fridley and Fridley 2010). The VARK learning style inventory developed by Fleming (2001) which is a sensory model was used in the current study to identify the participants' learning styles. The acronym stands for visual, auditory, read/write, and kinesthetic styles. The learning styles include 1) visual (learners with a visual learning style mostly learn through observation); 2) auditory (learners with an auditory learning style prefer to learn by listening and oral presentation of the contents); 3) read/write (learners with a read/write learning style learn by note taking and reading); and 4) kinesthetic (learners with a kinesthetic learning style learn through experiments, physical activities, and object manipulation). People's performances in different situations provided the basis for designing the VARK questionnaire items. The VARK questionnaire is a standard tool (Fleming and Mills 1992) and has been utilized at all levels of education (Cuevas 2015). In comparison to other learning styles models, this model is more straightforward to study as the categories are concrete and relate to our specific senses (Scott 2010). In addition, its validity and reliability were assessed and confirmed in some studies (Leite et al. 2010; Zhu et al. 2018). This suggested that it can be utilized as a predictor for a person's learning style. In addition to the acceptable, reliability and validity measures of VARK obtained in previous studies, a satisfactory test-retest reliability of 0.79 was also obtained in the current study.

\subsubsection{Stimulated recall interview}

Stimulated recall is a retrospective method for eliciting the thought processes involved in carrying out an activity and can evaluate the effects of recasts focusing on learners' cognitive processes (Gass and Mackey 2000). This method is intended to probe learners' perception of recasts and the extent to which recasts can engage 
learners in a cognitive comparison, or noticing (Ellis 1994). By using a stimulus, such as an audio or a video recording, learners are asked to report what they were thinking at the time of the activity. This way the researcher can decide whether recasts were noticed by the participant as uptake or whether the immediate repetition of the recasts cannot be considered as an indicator of noticing.

\subsubsection{Voice recording device}

To provide the stimulus for the stimulated recall interview sessions, the class presentations were recorded using a voice recording device. The participants were informed at the beginning of the study.

\subsection{Procedures}

In order to determine the participants' learning styles, the VARK questionnaire which consisted of 16 multiple choice items was administered among the participants in the first session. In this questionnaire, each item is related to a particular style. The participants selected the options according to their preferences, and if one choice did not show the whole view, they could select more options. Higher scores in each learning style indicated the participants' greater desire for that style. If an individual gets equal scores in two or more styles, his/her learning style was considered multimodal or mixed. The results of the questionnaire showed that seven participants were identified as visual, 10 as auditory, another 10 as read/ write, five as kinesthetic and 13 participants were identified as mixed style learners. For greater comparability, it was decided to consider an equal number of participants for each style. Therefore, from each style five participants were selected which yielded a final sample of 25 .

In the next sessions, the class presentations were recorded. Moreover, the researchers used note-taking to note who was speaking and what their preferred learning style was based on the VARK score. During the students' story retelling tasks, the instructor provided recasts on students' grammatical, lexical, and phonological errors. In cases where a student produced an utterance with more than one type of error, it was coded as the error type on which the recast focused. In the current study, recasts were provided extensively and randomly without targeting specific features following Ellis and Sheen (2006), who argued that preselecting target forms for intensive recasts in research settings can be of little significance for practicing teachers seeking implications for actual teaching. On average, in each session $30 \mathrm{~min}$ of the students' presentations were audiotaped. Ultimately around $400 \mathrm{~min}$ of the students' presentations were recorded. The 
recordings were examined later and the areas of interest (AOI) were transcribed and recast instances were highlighted.

Following Egi (2008) who argued that learners can recall recent activity more accurately, stimulated recall interviews were conducted a day after the class presentation. Due to the complexity of the information they were asked to deliver (e.g., what they were thinking or feeling at the time when recasts were given), sometimes the stimulated recall was carried out in the students' L1. As mentioned earlier, four different students had class presentations each session, thus the stimulated recall interviews were conducted for these four participants each week. In the interview sessions as they listened, the audios were periodically paused (usually during recast instances) and the learners were asked to report what they were thinking at that time. Before listening to the audio recordings, the students were given the recall instructions, which were adapted from previous studies (e.g., Egi 2004, cited in Egi 2008; Sato 2016). The passages or stories that their presentations were based on were also presented to the students to facilitate recall of thoughts (Al-Surmi 2012; Egi 2008). The interviewers listened passively to the participants' recall without being conversational partners who could ask leading questions (Egi 2008; Gass and Mackey 2000). Noticing was operationalized as the learners' verbalization of what they perceived the focus of feedback to be.

\section{Results}

The results of both online and retrospective methods of measuring noticing in the form of uptake and stimulated recall interviews are presented in Section 4.

The first research question investigated the noticing rate of the participants when encountering grammatical, lexical, or phonological recasts. To this end, the total number of grammatical, lexical,and phonological recasts, the number of noticed and unnoticed recasts and the percentage of noticed recasts for all the participants were considered. The total number of noticed recasts consisted of the sum of uptake and stimulated recall decisions regarding the noticing of recasts. A randomly selected $25 \%$ of the recast episodes and the stimulated recall data were coded by two independent coders and disagreements were resolved. Inter-coder reliability was calculated and a coefficient of 94.3 based on the overall percentage agreement was obtained. As mentioned earlier, each participant had four presentations during the course. In total around 1800 errors were made by the participants and around 1500 instances of recasts occurred during the presentations. Table 1 presents the results. 
Table 1: Total number and percentage of noticed and unnoticed recasts.

\begin{tabular}{|c|c|c|c|c|c|c|c|c|c|}
\hline \multirow[t]{2}{*}{ Styles } & \multicolumn{3}{|c|}{ Grammatical recasts } & \multicolumn{3}{|c|}{ Lexical recasts } & \multicolumn{3}{|c|}{ Phonological recasts } \\
\hline & Noticed & Unnoticed & $\%$ & Noticed & Unnoticed & $\%$ & Noticed & Unnoticed & $\%$ \\
\hline Visual & 66 & 100 & $39.7 \%$ & 27 & 30 & $47.3 \%$ & 39 & 43 & $47.5 \%$ \\
\hline Auditory & 98 & 98 & $50 \%$ & 30 & 20 & $60 \%$ & 32 & 20 & $61.5 \%$ \\
\hline Read/Write & 86 & 86 & $50 \%$ & 27 & 28 & $49.0 \%$ & 32 & 32 & $50 \%$ \\
\hline Kinesthetic & 68 & 101 & $40.2 \%$ & 17 & 35 & $32.6 \%$ & 25 & 40 & $38.4 \%$ \\
\hline Mixed & 83 & 94 & $46.8 \%$ & 37 & 36 & $50.6 \%$ & 32 & 38 & $45.7 \%$ \\
\hline Total & 401 & 479 & $45.3 \%$ & 138 & 149 & 47.9 & 160 & 173 & $48.6 \%$ \\
\hline
\end{tabular}

In order to see if there is a statistically significant difference among different learning styles, the Chi-square test of independence was run. The results are presented in Table 2.

As Table 2 indicates, the Chi-square statistic is 33.951. The $p$-value is 0.026 . Therefore, the result is significant at $p<0.05$. This means that there is a statistically significant difference among learning styles regarding the noticing of grammatical, lexical, and phonological recasts.

To see which style had a better noticing rate in comparison with other styles (the second research question) the total number of recast instances and the noticing rate obtained from the online and retrospective methods of measuring noticing was calculated. To access the following data, the recordings of participants' presentations were analyzed and the instances of uptake were calculated. Then the information obtained from the stimulated recall interview sessions was analyzed and the numbers of noticed recasts were calculated. Table 3 demonstrates the frequency of recasts, the number of noticed and unnoticed recasts and the noticing rates for each learning style.

To see whether there is a statistically significant difference between the variables of learning style and noticing, the Chi-square test of independence was run. Table 4 presents the results.

As Table 4 indicates, the Chi-square statistic is 16.31 The $p$-value is 0.038 . Therefore, the result is significant at $p<0.05$. This means that our five learning style

Table 2: Chi-square test of independence for different learning styles.

\begin{tabular}{lrrr}
\hline & Chi-Square & DF & $\boldsymbol{p}$ \\
\hline Pearson & 33.95 & 20 & 0.026 \\
Likelihood ratio & 35.32 & 20 & 0.018 \\
\hline
\end{tabular}


Table 3: Number of recasts, noticed, unnoticed, and noticing rate.

\begin{tabular}{lrrrr}
\hline Learning styles & Recast & Noticed & Unnoticed & Noticing rate \\
\hline Visual & 305 & 132 & 173 & $43.2 \%$ \\
Auditory & 298 & 160 & 138 & $53.6 \%$ \\
Read/write & 291 & 145 & 146 & $49.8 \%$ \\
Kinesthetic & 286 & 110 & 176 & $38.4 \%$ \\
Mixed style & 320 & 152 & 168 & $47.5 \%$ \\
Total & 1500 & 699 & 801 & $46.5 \%$ \\
\hline
\end{tabular}

Table 4: Chi-square test of independence for the variables of learning style and noticing.

\begin{tabular}{lrrr}
\hline & Chi-Square & DF & $\boldsymbol{p}$ \\
\hline Pearson & 16.31 & 8 & 0.038 \\
Likelihood Ratio & 16.39 & 8 & 0.037 \\
\hline
\end{tabular}

groups had a significant difference regarding the noticing of their teacher's feedback in the form of recasts. To see which style had a better noticing rate than others (where the significance comes from), the standardized residuals were taken into account. Table 5 displays the actual counts, the expected counts, and the standardized residuals, which indicates the magnitude and direction of difference between the actual and the expected counts.

As Table 5 shows, the auditory learning style received the largest standardized residual (1.79) which indicates that there were more noticing occurrences than expected and kinesthetic style received the lowest standardized residual $(-2)$ which indicates that there were less noticing incidences than expected in this style. Read/write and mixed learning styles had positive standardized residuals $(0.8,0.2)$ respectively. This shows that after auditory learning style, students with read/write and mixed learning styles noticed the teachers' corrective feedback in the form of recasts to a higher degree. Visual learning style received the residual of -0.8 which indicates that after kinesthetic learning style, this style received the lowest recast noticing rate.

The third research question intended to investigate the association between learning style and linguistic focus of recast. As Table 2 indicated, the participants had a significant difference regarding the noticing of grammatical, lexical, and phonological recasts. To see the performance of each style in each recast type (grammatical, lexical, and phonological) and the possible relationships, the standardized residuals were taken into account. Table 6 displays the actual counts, 
Table 5: Rows: learning styles columns: recast noticing.

\begin{tabular}{lrrrr}
\hline & Recast frequency & Noticed recasts & Unnoticed recasts & All \\
\hline Visual & 305 & 132 & 173 & 610 \\
& 305.0 & 142.1 & 162.9 & \\
Auditory & 0.00 & -0.85 & 0.79 & \\
& 298 & 160 & 138 & 596 \\
Read/write & 298.0 & 138.9 & 159.1 & \\
& 0.0000 & 1.79 & -1.68 & \\
Kinesthetic & 291 & 145 & 146 & 582 \\
& 291.0 & 135.6 & 155.4 & \\
Mixed & 0.00 & 0.81 & -0.75 & \\
& 286 & 110 & 176 & 572 \\
All & 286.0 & 133.3 & 152.7 & \\
& 0.00 & -2.02 & 1.88 & \\
& 320 & 152 & 168 & 640 \\
& 320.0 & 149.1 & 170.9 & \\
& 0.00 & 0.24 & -0.22 & \multirow{2}{*}{0} \\
& 1500 & 699 & 801 & 3000 \\
\hline
\end{tabular}

the expected counts, and the standardized residuals, which indicates the magnitude and direction of difference between the actual and the expected counts.

As is clear from Table 6, the auditory learning style received a standardized residual of 2.1 indicating that this style received the best noticing rate of grammatical recasts and the visual learning style received a standard residual of -1.7 indicating that this style received the worst noticing rate of grammatical recasts. The read/write style had a positive residual of 0.9. This indicates the $\mathrm{read} /$ write style received the second noticing rate regarding grammatical recasts after the auditory style. Mixed and kinesthetic styles received negative standardized residuals of -1.0 and -0.3 respectively. This indicates that after the visual style, the mixed, and kinesthetic styles had the worst noticing rate of grammatical recasts.

Regarding the noticing of lexical recasts, mixed style participants had the best performance with a standardized residual of 1.4 and the kinesthetic style participants had the worst performance with a residual of -1.8 . Auditory style participants received a residual of 0.5 indicating a better lexical recasts noticing than kinesthetic and visual styles.

The visual learning style group which received negative residuals in grammatical and lexical recasts noticing received a residual of 1.1, making it the leading group in noticing phonological recasts. The kinesthetic style, which also received the lowest residual in lexical recasts noticing, received a residual of -1.0 indicating 
Table 6: Tabulated statistics: learning style, recast noticing.

\begin{tabular}{|c|c|c|c|c|c|c|c|}
\hline & $\begin{array}{r}\text { Noticed } \\
\text { grammatical } \\
\text { recasts }\end{array}$ & $\begin{array}{r}\text { Unnoticed } \\
\text { grammatical } \\
\text { recasts }\end{array}$ & $\begin{array}{l}\text { Noticed } \\
\text { lexical } \\
\text { recasts }\end{array}$ & $\begin{array}{r}\text { Unnoticed } \\
\text { lexical } \\
\text { recasts }\end{array}$ & $\begin{array}{r}\text { Noticed } \\
\text { phonological } \\
\text { recasts }\end{array}$ & $\begin{array}{r}\text { Unnoticed } \\
\text { phonological } \\
\text { recasts }\end{array}$ & All \\
\hline \multirow[t]{3}{*}{ Visual } & 66 & 100 & 27 & 30 & 39 & 43 & 305 \\
\hline & 81.54 & 97.40 & 28.06 & 30.30 & 32.53 & 35.18 & \\
\hline & -1.72 & 0.26 & -0.20 & -0.05 & 1.13 & 1.32 & \\
\hline \multirow[t]{3}{*}{ Auditory } & 98 & 98 & 30 & 20 & 32 & 20 & 298 \\
\hline & 79.67 & 95.16 & 27.42 & 29.60 & 31.79 & 34.37 & \\
\hline & 2.05 & 0.29 & 0.49 & -1.76 & 0.04 & -2.45 & \\
\hline \multirow[t]{3}{*}{ Read/write } & 86 & 86 & 27 & 28 & 32 & 32 & 291 \\
\hline & 77.79 & 92.93 & 26.77 & 28.91 & 31.04 & 33.56 & \\
\hline & 0.93 & -0.72 & 0.04 & -0.17 & 0.17 & -0.27 & \\
\hline \multirow[t]{3}{*}{ Kinesthetic } & 68 & 101 & 17 & 35 & 25 & 40 & 286 \\
\hline & 76.46 & 91.33 & 26.31 & 28.41 & 30.51 & 32.99 & \\
\hline & -0.97 & 1.01 & -1.82 & 1.24 & -1.00 & 1.22 & \\
\hline \multirow[t]{3}{*}{ Mixed } & 83 & 94 & 37 & 36 & 32 & 38 & 320 \\
\hline & 85.55 & 102.19 & 29.44 & 31.79 & 34.13 & 36.91 & \\
\hline & -0.28 & -0.81 & 1.39 & 0.75 & -0.37 & 0.18 & \\
\hline All & 401 & 479 & 138 & 149 & 160 & 173 & 1500 \\
\hline
\end{tabular}

the worst performance in noticing the phonological recasts. The mixed style with the negative residual of -0.4 was placed after the kinesthetic style. The read/write and visual styles had the best noticing rate following the auditory style, with residuals of 0.2 and 0.04 respectively.

\section{Discussion}

The present study investigated the association between the linguistic focus of recasts, learning styles, and noticing. Based on the results, a significant difference was observed between learning styles regarding the noticing of teachers' $\mathrm{CF}$ in the form of recasts. This is in line with Evans and Waring (2011), Hashemian and Farhangju (2018), Rahimi (2015), and Yoshida (2008) who also provided evidence for the moderating effects of learning styles and the efficacy of CF. The results are in contrast with Tasdemir and Arslan (2018) and Wahyuni (2017) as they found that the concept of learning styles is irrelevant for understanding learner feedback preferences.

More specifically, the results showed that the auditory learning style received the highest noticing rate and the kinesthetic learning style received the lowest. After the auditory learning style, the read/write and mixed learning styles noticed 
the teachers' corrective feedback to a higher degree. The visual learning style received the lowest noticing rate following the kinesthetic style. This is partly in line with Rassaei (2015) who also found that learning styles benefited differently from recasts and partly in contrast with it as it was found that only FieldIndependent (FI) learners benefited from recasts. FI individuals are those who pay more attention to less salient cues in context and are able to extract relevant visual cues. This is very close to visual styles in the current study who received the lowest noticing rate following the kinesthetic style. One possible explanation for the high noticing rate obtained by the auditory learning styles might be the fact that recasts were provided in the class through speech which is considered as an audio stimulus favored by the auditory style learners. Moreover, the audio recordings of the learners' presentations were used in the stimulated recall interviews which again favored auditory styles more than the other styles. It is for future studies to explore whether providing learners with other forms of stimulus (e.g., video recordings) in the stimulated recall interviews would lead to different results.

The groups further showed a significant difference regarding the noticing of grammatical, lexical, and phonological recasts. Grammatical recasts were noticed better by learners whose learning style was auditory, lexical recasts were better noticed by learners whose learning style was mixed and phonological recasts were better noticed by learners whose learning style was visual. Therefore, providing grammatical recasts for visual learners and lexical and phonological recasts for kinesthetic learners may be less effective due to their low noticing rate. Only auditory and read/write styles received positive residuals which indicated they had a better noticing rate than expected. This shows that recasts were effective for these styles irrespective of their linguistic focus. The fact that the residuals obtained by other styles were both positive and negative shows that when dealing with students from visual, kinesthetic, and mixed styles, teachers should be selective in providing recasts. Based on the results, teachers are recommended to provide more grammatical recasts for auditory styles, more lexical recasts for mixed styles and more phonological recasts for visual styles, if they want their recasts to be more effective. The findings of the current study provided some empirical evidence in support of the learning style hypothesis that students learn in different ways and in contrast with Hussman and O'Loughlin (2018) who claimed that the conventional wisdom about learning styles should be rejected by educators and students alike.

\section{Conclusions and implications}

The objectives of this study were to investigate the association between the linguistic focus of recasts, learning styles, and noticing. The research questions were 
successfully answered according to the results. The results indicated that the auditory learning style received the highest noticing rate and the kinesthetic learning style received the lowest. After the auditory learning style, the read/write and mixed learning styles noticed the teachers' corrective feedback to a higher degree. The visual learning style received the lowest noticing rate following the kinesthetic style. The study further revealed that the groups had a significant difference regarding the noticing of grammatical, lexical, and phonological recasts. Grammatical recasts were noticed better by learners whose learning style was auditory, lexical recasts were better noticed by learners whose style was mixed, and phonological recasts were better noticed by visual learners. The results also showed that providing grammatical recasts for visual style learners and lexical and phonological recasts for kinesthetic style learners cannot be very effective due to their low noticing rates. The current study showed that the match between learning styles and recasts can facilitate noticing. Therefore, both learners and teachers should be more cognizant of learning styles and try to take into account the features which can enhance the noticing of recasts. The findings of the current study can help educational institutions train their teachers to be more selective in providing $\mathrm{CF}$ and this will definitely lead to a better noticing rate which is the ultimate goal of correction.

\section{References}

Al-Surmi, Mansoor. 2012. Learners' noticing of recasts of morpho-syntactic errors: Recast types and delayed recognition. System 40. 226-236.

Bhat, Mehraj. 2014. Understanding the learning styles and its influence on teaching/learning process. International Journal of Education and Psychological Research 3(1). 9-13.

Bigelow, Martha, Robert Delmas, Kit Hansen \& Elaine Tarone. 2012. Literacy and the processing of oral recasts in SLA. Tesol Quarterly 40(4). 665-689.

Choi, Seung-Yi \& Li Shaofeng. 2012. Corrective feedback and learner uptake in a child ESOL classroom. RELC Journal 43(3). 331-351.

Cuevas, Joshua. 2015. Is learning styles-based instruction effective? A comprehensive analysis of recent research on learning styles. Theory and Research in Education 13(3). https://doi.org/ $10.1177 / 1477878515606621$.

Dörnyei, Zoltan. 2005. The psychology of the language learner: Individual differences in second language acquisition. Mahwah, NJ: Lawrence Erlbaum Associates.

Egi, Takako. 2008. Investigating stimulated recall as a cognitive measure: Reactivity and verbal reports in SLA research methodology. Language Awareness 17. 212-228.

Ellis, Rod. 1994. The study of second language acquisition. Oxford: Oxford University Press.

Ellis, Rod. 2006. Modelling learning difficulty and second language proficiency: The differential contributions of implicit and explicit knowledge. Applied Linguistics 27. 431-463. 
Ellis, Rod \& Younghee Sheen. 2006. Reexamining the role of recasts in second language acquisition. Studies in Second Language Acquisition 28(4). 575-600.

Ellis, Rod, Helen Basturkmen \& Shawn Loewen. 2001. Learner uptake in communicative ESL lessons. Language Learning 51. 281-318.

Erlam, Rosemary \& Shawn Loewen. 2010. Implicit and explicit recasts in L2 oral French interaction. Canadian Modern Language Review 66. 877-905.

Evans, Carol \& Michael Waring. 2011. Enhancing feedback practice: A personal learning styles pedagogy approach. In Stephen Rayner \& Eva Cools (eds.), Style differences in cognition, learning, and management: Theory, research and practice, 188-203. New York: Routledge.

Ferris, Dana R. 2010. Second language writing research and written corrective feedback in SLA. Studies in Second Language Acquisition 32(2). 181-201.

Fleming, Neil D. 2001. Teaching and learning styles: VARK strategies. Christchurch, New Zealand: N.D. Fleming.

Fleming, Neil. D. \& Colleen Mills. 1992. Helping students understand how they learn. The Teaching Professor 7(4). Madison, Wisconsin, USA: Magma Publications.

Fridley, William Lloyd \& Carolyn Althoff Fridley. 2010. Some problems \& peculiarities with the learning styles rhetoric and practice. Journal of Philosophy \& History of Education 60. 21-27.

Gass, Susan \& Alison Mackey. 2000. Stimulated recall methodology in second language research. Mahwah, NJ: Lawrence Erlbaum Associates.

Goo, Jaemyung. 2012. Corrective feedback and working memory capacity in interaction driven L2 learning. Studies in Second Language Acquisition 34. 445-474.

Granena, Gisela \& Yucel Yilmaz. 2018. Corrective feedback and the role of implicit sequence learning ability in L2 online processing. Language Learning 69(1). 127-156.

Gursynski-Weiss, Laura. 2016. Factors influencing spanish instructors' in-class feedback decisions. The Modern Language Journal 100(1). 255-275.

Hashemian, Mahmood \& Maryam Farhangju. 2018. Effects of metalinguistic feedback on grammatical accuracy of Iranian field (in)dependent L2 learners' writing ability. Journal of Research in Applied Linguistics 9. 141-161.

Husmann, Polly R. \& Valerie Dean O’Loughlin. 2018. Another nail in the coffin for learning styles? Disparities among undergraduate anatomy students' study strategies, class performance, and reported VARK learning styles. Anatomical Sciences Education 12(1). 6-19.

Kaivanpanah, Shiva, Pooneh Yamouty \& Hossein Karami. 2012. Examining the effects of proficiency, gender, and task type on the use of communication strategies. Porta Linguarum 17. 79-93.

Kim, Jihyun \& Zhao Hong Han. 2007. Recasts in communicative EFL classes: Do teacher intent and learner interpretation overlap? In A. Mackey (ed.), Conversational interaction in second language acquisition: A collection of empirical studies. Oxford: Oxford University Press.

Kim, Youlin, Caroline Payant \& Pamela Pearson. 2015. The intersection of task-based interaction, task complexity, and working memory. Studies in Second Language Acquisition 37(3). 549-581.

Leite, Walter, Marilla Svinicki \& Yuying Shi. 2010. Attempted validation of the scores of the VARK: Learning styles inventory with multitrait-multimethod confirmatory factor analysis models. Educational and Psychological Measurement 70(2). 323-339.

$\mathrm{Li}$, Shaofeng. 2010. The effectiveness of corrective feedback in SLA: A meta-analysis. Language Learning 60(2). 309-365.

$\mathrm{Li}$, Shaofeng. 2013. The interactions between the effects of implicit and explicit feedback and individual differences in language analytic ability and working memory. The Modern Language Journal 97. 634-654. 
Li, Shaofeng. 2017. Student and teacher beliefs and attitudes about oral corrective feedback. In Eva Kartchava \& Hossein Nassaji (eds.), Corrective feedback in second language teaching and learning: Research, theory, applications, implications, 143-157. New York, NY: Routledge.

Li, Shaofeng, Yan Zhu \& Rod Ellis. 2016. The effects of the timing of corrective feedback on the acquisition of a new linguistic structure. The Modern Language Journal 100. 276-295.

Loewen, Shawn \& Masatoshi Sato. 2018. Interaction and instructed second language acquisition. Language Teaching 51(3). 285-329.

Long, Mike. 2015. Second language acquisition and task-based language teaching. Malden: Wiley Blackwell.

Lyster, Roy \& Leila Ranta. 1997. Corrective feedback and learner uptake: Negotiation of form in communicative classrooms. Studies in Second Language Acquisition 19. 37-66.

Lyster, Roy \& Kazuya Saito. 2010. Oral feedback in classroom SLA: A meta-analysis. Studies in Second Language Acquisition 32(2). 265-302.

Mackey, Alison, Susan Gass \& Kim McDonough. 2000. How do learners perceive interactional feedback? Studies in Second Language Acquisition 22. 471-497.

Mackey, Alison, Maymona Al-Khalil, Gergana Atanassova, Mika Hama, Aubrey Logan-Terry \& Kimi Nakatsukasa. 2007. Teachers' intentions and learners' perceptions about corrective feedback in the L2 classroom. International Journal of Innovation in Language Learning and Teaching 1(1). 129-152.

Nicholas, Howard, Patsy M. Lightbown \& Nina Spada. 2001. Recasts as feedback to language learners. Language Learning 51. 719-758.

Oxford, Rebecca L. 2011. Teaching and researching language learning strategies. London: Pearson/Longman.

Parlak, Özgür \& Nicole Ziegler. 2017. The impacts of recasts on the development of primary stress in a synchronous computer mediated environment. Studies in Second Language Acquisition 39(2). https://doi.org/10.1017/S0272263116000310.

Rahimi, Mohammad. 2015. The role of individual differences in learners' retention of written corrective feedback. Journal of Response to Writing 1(1). 19-48.

Rassaei, Ehsan. 2015. Recasts, field dependence/independence cognitive style, and L2 development. Language Teaching Research 19(4). 499-518.

Révész, Andrea. 2012. Working memory and the observed effectiveness of recasts on different L2 outcome measures. Language Learning 62(1). 93-132.

Sato, Rintaro. 2016. Exploration into the effects of recast types on advanced-level japanese efl learners' noticing. Electronic Journal of Foreign Language Teaching 13(2). 260-274.

Sato, Masatoshi \& Shawn Loewen. 2018. Metacognitive instruction enhances the effectiveness of corrective feedback: Variable effects of feedback types and linguistic targets. Language Learning 68(2). 507-545.

Schmidt, Richard W. 1990. The role of consciousness in second language learning. Applied Linguistics 11(2). 129-158.

Scott, Catherine. 2010. The enduring appeal of learning styles. Australian Journal of Education 54(1). 5-17.

Sheen, Younghee. 2004. Corrective feedback and learner uptake in communicative classrooms across instructional settings. Language Teaching Research 8. 263-300.

Sheen, Younghee. 2006. Exploring the relationship between characteristics of recasts and learner uptake. Language Teaching Research 10. 361-392. 
Sheen, Younghee. 2007. The effect of focused written corrective feedback and language aptitude on ESL learners' acquisition of articles. Tesol Quarterly 41(2). 255-283.

Sheen, Younghee. 2008. Recasts, language anxiety, modified output, and L2 learning. Language Learning 58(4). 835-874.

Suzuki, Wataru, Hossein Nassaji \& Konosuke Sato. 2019. The effects of feedback explicitness and type of target structure on accuracy in revision and new pieces of writing. System 81. 135-145.

Tasdemir, Muhammed Salih \& Fadime Yalcin Arslan. 2018. Feedback preferences of EFL learners with respect to their learning styles. Cogent Education 5(1). https://doi.org/10.1080/ 2331186X.2018.1481560.

Trofimovich, Pavel, Ahlem Ammar \& Elizabeth Gatbonton. 2007. How effective are recasts? The role of attention, memory, and analytical ability. In Allison Mackey (ed.), Conversational interaction in second language acquisition, 144-171. Oxford: Oxford University Press.

Wahyuni, Sri. 2017. The effect of different feedback on writing quality of college students with different cognitive styles. Dinamika Ilmu 17(1). https://doi.org/10.21093/di.v17i1.649.

Willingham, Daniel T., Elizabeth M. Hughes \& David G. Dobolyi. 2015. The scientific status of learning styles theories. Teaching of Psychology. 42(3). 266-271.

Yılmaz, Yucel. 2012. The relative effects of explicit correction and recasts on two target structures via two communication modes. Language Learning 62. 1134-1169.

Yoshida, Reiko. 2008. Learners' perception of corrective feedback in pair work. Foreign Language Annals 41(3). 525-541.

Zhao, Yongbin \& Rod Ellis. 2020. The relative effects of implicit and explicit corrective feedback on the acquisition of 3rd person -s by Chinese university students: A classroom based study. Language Teaching Research 24(2). 1-21.

Zhu, Hong-rui, Hui Zeng, Hua Zhang, Hong-yu Zhang, Feng-jing Wan, Hong-hua Guo \& Cai-hong Zhang. 2018. The preferred learning styles utilizing VARK among nursing students with bachelor degrees and associate degrees in China. Acta Paulista de Enfermagem 31(2). 162-169.

\section{Bionotes}

\section{Mojtaba Tadayonifar}

English Translation Department, Kashmar Higher Education Institute, Kashmar, Iran https://orcid.org/0000-0002-1448-4216

Mojtaba Tadayonifar holds an M.A. in TEFL from Payeme Noor University, Tehran (PNU). He is currently an instructor at Kashmar Higher Education Institute, Iran. His research interests include corrective feedback (CF), task-based language teaching (TBLT), glossing, and learning styles.

\section{Mahnaz Entezari}

English Translation Department, Kashmar Higher Education Institute, Kashmar, Iran

Mahnaz Entezari holds an M.A in TEFL from Payeme Noor University, Tehran (PNU). She is currently an instructor at Kashmar Higher Education Institute, Iran. Her research interests include reading strategies, glossing, and learning styles. She is also interested in translation studies. 


\section{Mostafa Bahraman}

English Translation Department, Kashmar Higher Education Institute, Kashmar, Iran

Mostafa Bahraman holds a Ph.D. in Translation Studies from University Sains Malaysia. He is an assistant professor at Kashmar Higher Education Institute. He is specifically interested in figurative language, assessment, and audiovisual translation (AVT). 
Reproduced with permission of copyright owner.

Further reproduction prohibited without permission. 